\title{
Ajuste osmótico em milho cultivado em diferentes sistemas de manejo de solo e disponibilidade hídrica
}

\author{
Cleusa Adriane Menegassi Bianchi(1) ${ }^{\text {João Ito Bergonci(1) }{ }^{(1)} \text { Homero Bergamaschi(1) e Genei Antonio Dalmago }}{ }^{(1)}$
}

(1)Universidade Federal do Rio Grande do Sul, Caixa Postal 15100, CEP 91501-970 Porto Alegre, RS. E-mail: cleusa_bianchi@yahoo.com.br, joao.bergonci@ufrgs.br, homerobe@ufrgs.br, gdalmago@yahoo.com.br

Resumo - A cultura do milho é sensível ao déficit hídrico, e esta é uma causa freqüente de redução na produção de grãos. O objetivo deste trabalho foi verificar a ocorrência de ajuste osmótico em milho, cultivado em dois sistemas de manejo do solo, com diferentes disponibilidades hídricas. Os tratamentos consistiram do cultivo do milho em semeadura direta (SD) e convencional (SC), com irrigação de forma a manter a umidade do solo próxima à capacidade de campo, e sem irrigação. O ajuste osmótico foi obtido pela diferença do potencial osmótico hidratado entre as plantas irrigadas e sem irrigação. Os maiores valores de potencial mínimo de água na folha ocorreram em plantas cultivadas sob SD, em razão do maior potencial matricial da água no solo nesse sistema. O potencial de pressão e o osmótico hidratado diminuíram em conseqüência do déficit hídrico, o que determinou a ocorrência de ajuste osmótico em ambos os sistemas, que foi mais intenso em manejo convencional. Portanto, o potencial mínimo de água na folha demonstra ser um indicador adequado da condição hídrica das plantas de milho. A cultura apresenta tolerância ao déficit hídrico por meio do mecanismo de ajuste osmótico.

Termos de indexação: Zea mays, potencial de água na folha, déficit hídrico, plantio direto.

\section{Osmotic adjustment in maize cultivated in different soil tillage systems and water availability}

\begin{abstract}
Maize is a very sensible crop to water deficit, which is a frequent cause of reduction in its grain yield. The objective of this work was to verify the occurrence of osmotic adjustment in maize cultivated in different soil management systems and water availability. The maize was cropped in no-tillage (NT) and conventional tillage (CT), with irrigation and no-irrigation. For measurements of minimum leaf water potential, a pressure chamber was utilized. Osmotic adjustment was calculated as the difference between osmotic potentials at full turgor, in irrigated and non-irrigated plants. Highest values of minimum leaf water potential were found in plants cropped in NT, as a response to the highest soil potential on this cropping system. Pressure potential and the osmotic potential at full turgor were reduced as a response to water deficit, resulting on an osmotic adjustment in both cropping systems, with a highest intensity in the CT system. Minimum leaf water potential showed sensitivity to water deficit, which makes it a good indicator of plant water status on maize. Maize crop showed tolerance to water deficit through the mechanism of osmotic adjustment.
\end{abstract}

Index terms: Zea mays, leaf water potential, water deficit, no-tillage.

\section{Introdução}

O milho é uma cultura de grande importância socioeconômica para o Estado do Rio Grande do Sul. Seu rendimento é extremamente dependente da condição hídrica durante o desenvolvimento, principalmente no período de pendoamento-espigamento (Matzenauer et al., 1995; Bergamaschi et al., 2004). Assim, qualquer aporte de água durante esse período pode ser fator determinante em seu rendimento final.

A atividade agrícola teve importantes modificações nas últimas décadas, como a adoção do sistema de se- meadura na palha, denominado plantio direto, que provoca alterações nas propriedades físicas (Derpsch et al., 1986), químicas (Sidiras et al., 1983) e biológicas do solo (Griffith et al., 1992). Em relação à resposta das plantas, quanto à disponibilidade de água, pouco se sabe a respeito do efeito desse sistema em comparação ao convencional.

A utilização de indicadores da condição hídrica das plantas, como o potencial de água na folha, pode ser uma ferramenta importante no monitoramento da disponibilidade de água no solo e da necessidade de irrigação (Bergonci et al., 2000). 
O potencial da água é uma medida importante e sensível do estado hídrico da planta; varia de valores próximos de zero nas plantas sem estresse, até valores bem abaixo de zero ou igual ao potencial osmótico, em plantas com estresse severo (Kramer \& Boyer, 1995). Mesmo com variações ao longo do dia - estresse de curto prazo -, em plantas irrigadas, o potencial de água na folha tem sido utilizado em estudos das relações hídricas dos vegetais (Hsiao, 1973), e é considerado padrão do estado hídrico da planta.

Diversos autores procuraram estabelecer relações entre o potencial da água e determinados parâmetros da planta. Boyer (1970) determinou que potenciais da água na planta de milho menores que -0,4 MPa afetavam significativamente a expansão foliar, embora a fotossíntese máxima ocorresse com potenciais foliares entre -0,6 e -0,8 MPa. Bergonci et al. (2000) observaram que, acima de determinado potencial mínimo de água na folha, entre -1,2 e -1,5 MPa, as plantas de milho recuperavam sua condição hídrica, após o fechamento estomático, e esses valores poderiam ser utilizados como critério indicador de déficit hídrico do milho.

Na presença de déficit hídrico, as plantas podem utilizar mecanismos de tolerância, como o ajuste osmótico, para que a célula absorva água e mantenha o potencial de pressão em níveis adequados. A diminuição do potencial osmótico, em reposta ao déficit hídrico, pode resultar de uma concentração passiva de solutos, conseqüência da desidratação da célula, ou da acumulação ativa de solutos, mas só esta última pode ser considerada como ajuste osmótico (Patakas et al., 2002).

Premachandra et al. (1992), ao estudarem cinco cultivares de milho submetidas ao déficit hídrico, observaram que o potencial osmótico diminuiu, em todas as cultivares, em resposta ao decréscimo do teor de água no solo. De acordo com os mesmos autores, alta acomodação osmótica foi observada, com valores entre 0,08 e 0,43 MPa. Jongdee et al. (2002) observaram, no arroz, ajuste osmótico com valores de 0,8 MPa, dependente da severidade do déficit. Apesar de ser considerado um importante mecanismo de tolerância ao déficit hídrico, o ajuste osmótico pode não aumentar a produtividade das plantas, mas possibilita a continuação do desenvolvimento em condições de estresse (Serraj \& Sinclair, 2002).

O objetivo deste trabalho foi verificar a ocorrência de ajuste osmótico em milho, cultivado em diferentes sistemas de manejo do solo, com diferentes disponibilidades hídricas.

\section{Material e Métodos}

O experimento foi realizado na Estação Experimental Agronômica, da Universidade Federal do Rio Grande do Sul (EEA/UFRGS), Município de Eldorado do Sul, RS ( $30^{\circ} 5^{\prime} \mathrm{S}, 5^{\circ} 40^{\prime} \mathrm{W}$ e $40 \mathrm{~m}$ de altitude). O clima da região é do tipo fundamental Cfa, conforme a classificação climática de Köppen, ou seja, subtropical úmido com verão quente (Bergamaschi et al., 2003).

$\mathrm{O}$ solo pertence à unidade de mapeamento Arroio dos Ratos, classificado como Argissolo Vermelho distrófico típico (Embrapa, 1999).

A área experimental de aproximadamente 0,5 ha foi cultivada por sete anos, desde 1995, parte em sistema de manejo semeadura direta (SD) e parte em semeadura convencional (SC). O preparo do solo foi feito em outubro de 2002, quando a área sob SD teve a cobertura vegetal dessecada e, posteriormente, acamada com o auxílio de rolo faca. No mesmo período, fez-se a incorporação da biomassa verde de aveia+ervilhaca, mediante aração com arado de disco, seguida de duas gradagens com grade niveladora, na área de SC.

Utilizou-se um delineamento em blocos (faixas) com quatro repetições. Os tratamentos consistiram de dois sistemas de manejo e dois níveis de água: sem irrigação (NI) e com irrigação, para manter a umidade do solo próxima à da capacidade de campo (I). Os dois sistemas de manejo foram dispostos em faixas nas parcelas principais, e os níveis de água, nas subparcelas. Utilizou-se um sistema de irrigação por aspersão em linha, constituído por 12 aspersores, dispostos na direção leste-oeste, entre os dois sistemas de manejo de solo.

Foram aplicados, na linha de semeadura, $800 \mathrm{~kg} \mathrm{ha}^{-1}$ de NPK 5-20-20. Posteriormente, foram aplicados $100 \mathrm{~kg} \mathrm{ha}^{-1}$ de $\mathrm{N}$ em cobertura (uréia), aos 15 e 36 dias após a emergência (DAE).

As medidas de potencial matricial da água no solo foram feitas com o auxílio de tensiômetros de mercúrio, instalados a $45 \mathrm{~cm}$ e $60 \mathrm{~cm}$ de profundidade.

O potencial mínimo da água na folha foi medido entre 12h e 13h, com câmara de pressão Soilmoisture modelo 3000. Foram cortados cerca de $35 \mathrm{~cm}$ da extremidade foliar, de folhas totalmente desenvolvidas e expostas ao sol. De imediato, dividiu-se a folha transversalmente; a extremidade era utilizada para medir o potencial da água; para tanto, retirou-se cerca de $5 \mathrm{~cm}$ da lâmina foliar, de forma a deixar a nervura central formando um pseudo-pecíolo. 
Após a leitura do potencial da água, parte da folha, em torno de $4 \mathrm{~g}$, foi colocada dentro de seringas de $3 \mathrm{~mL}$, que foram imediatamente colocadas em caixa de isopor e congeladas com $\mathrm{N}$ líquido, constituindo a amostra nãohidratada para determinação do potencial osmótico. A outra metade da folha foi colocada em frascos de vidro, com água para hidratação por um período de 12 horas, a fim de atingirem a saturação. Após esse período, coletou-se parte da folha ( 3 a $5 \mathrm{~g}$ ), que foi acondicionada em seringa de $3 \mathrm{~mL}$ e congelada em $\mathrm{N}$ líquido, constituindo a amostra hidratada para determinação do potencial osmótico. Os segmentos das folhas, congelados dentro das seringas, foram pressionados com o êmbolo para extração da seiva. A osmolaridade foi determinada em microsmômetro Wescor modelo 5520, e o potencial osmótico foi calculado segundo a equação de Van’t Hoff.

O ajuste osmótico foi calculado pela diferença entre o potencial osmótico das folhas hidratadas, das plantas irrigadas próximo à capacidade de campo, e o potencial osmótico das folhas hidratadas das plantas não-irrigadas.

Pela diferença entre o potencial da água mínimo total (osmótico+pressão) e o osmótico, determinado em folhas não-hidratadas, obteve-se o potencial de pressão.

Procedeu-se, também, ao cálculo da evapotranspiração de referência (ETo) pelo método de Penman (1948).

Os dados obtidos foram submetidos à análise de variância, e as médias foram comparadas pelo teste de Tukey, adotando-se como critério de significância valores de $\mathrm{P} \leq 0,05$.

\section{Resultados e Discussão}

No período inicial de desenvolvimento da cultura, ocorreram precipitações pluviais acima da média (Figura 1). No final de dezembro e início de janeiro, houve um pequeno déficit hídrico, causado pela ausência de chuva. Como as plantas estavam no período vegetativo, a demanda por água ainda era baixa, em razão do reduzido índice de área foliar, e isto não acarretou déficit hídrico para a cultura.

A partir de 54 DAE, 25 de janeiro, observou-se uma situação de déficit hídrico, caracterizada pela ausência de precipitação, e pela radiação solar global elevada, o que causou um aumento na evapotranspiração de referência (ETo). Nesse período, a cultura de milho encontrava-se com elevado índice de área foliar e em período crítico (pendoamento-espigamento), quando a falta de água intensifica o efeito do déficit hídrico na produtivi- dade final de grãos. Após a ocorrência do déficit hídrico, no início de fevereiro, ocorreram precipitações que totalizaram $196 \mathrm{~mm}$, valor bem acima da média histórica de 110,9 mm. Essa situação possibilitou a recuperação hídrica da cultura.

A produtividade final da cultura não diferiu, estatisticamente, entre os sistemas de manejo do solo. Nas parcelas sem irrigação, a produtividade foi de $1.355 \mathrm{~kg} \mathrm{ha}^{-1} \mathrm{e}$ $1.451 \mathrm{~kg} \mathrm{ha}^{-1} \mathrm{em}$ SD e SC, respectivamente. Com irrigação, a produtividade foi de $8.064 \mathrm{~kg} \mathrm{ha}^{-1}$, em SD, e de $9.596 \mathrm{~kg} \mathrm{ha}^{-1}$, em SC.

Na Figura 2 está representado o potencial mínimo da água na folha ( $\left.\psi_{\text {mín }}\right)$ de milho, medido em alguns dias, durante a condução do experimento. De maneira geral,

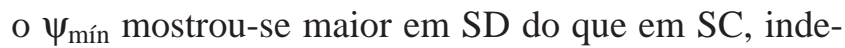
pendentemente do nível de irrigação, embora as diferenças não tenham sido estatisticamente significativas. Apesar disso, e do fato de não ter havido interação entre os fatores, optou-se por fazer a descrição dos resultados, comparando-se os sistemas de manejo nos dois níveis de irrigação, levando-se em consideração o desvio padrão das médias. Com isso, buscou-se avaliar a tendência da evolução temporal dos processos, potencial da água na folha e ajuste osmótico, em semeadura direta, uma vez que o processo evolutivo, desse sistema de manejo, é diferente do observado no sistema de semeadura convencional, que é mais lento e interrompido a cada preparo (Dalmago, 2004).

Nas parcelas sem irrigação, ocorreram os valores mais negativos de $\psi_{\text {mín }}$, comparados às parcelas irrigadas (Figura 2). Essa diferenciação indica que o $\psi_{\text {mín }}$ pode ser um indicador adequado da condição hídrica de plantas de milho, quando estabelecidas condições contrastantes de umidade no solo (Bergonci et al., 2000).

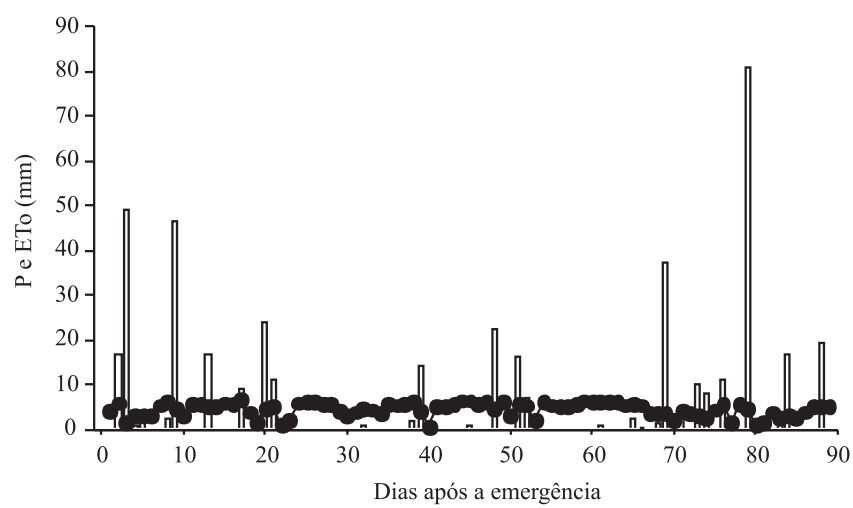

Figura 1. Precipitação pluvial (P, $\square$ ) e evapotranspiração de referência $(\mathrm{ETo}, \mathbf{O})$ em relação a dias após a emergência . 
Assim, o $\psi_{\text {mín }}$ pode ser utilizado para identificar uma condição de estresse já estabelecida.

Nas parcelas sem irrigação, podem ser observados três pontos importantes (Figura 2). O primeiro representa o $\psi_{\text {mín }}$ com valores altos, no primeiro dia de medição (42 DAE), que é maior em semeadura direta. Isso ocorreu, porque havia mais água disponível às plantas no solo sob SD do que sob SC, o que determinou maior $\psi_{\text {mín }}$ nas plantas sob SD, tendo estas então uma melhor condição hídrica.

O segundo ponto é aquele em que o $\psi_{\text {mín é seme- }}$ lhante entre os sistemas de manejo, aos 44 e 46 DAE. Nesses dias, o $\psi_{\text {mín }}$ foi igual a -1,5 MPa em ambos os sistemas. Isto mostra que as plantas apresentaram uma adequada condição hídrica, pois conforme Bergonci et al. (2000), o potencial mínimo da água na folha, de -1,5 MPa, indica, em milho, a não ocorrência de déficit hídrico, pois há recuperação do $\psi_{\text {mín }}$ ao final do dia, com o fechamento estomático. Tal diminuição do $\psi_{\text {mín }}$ resulta de um déficit de curto prazo, causado pela alta demanda evaporativa da atmosfera, quando a transpiração supera a absorção (Kramer \& Boyer, 1995).

O terceiro ponto representa os quatro dias finais de medidas, em que o $\psi_{\text {mín }}$ foi maior em SD, quando com- parado ao sistema de SC. Aos 58 e 64 DAE, o $\psi_{\text {mín }}$ diminuiu quando comparado aos dias anteriores de lei-

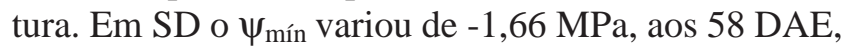
a -2,08 $\mathrm{MPa}$ aos $64 \mathrm{DAE}$, um pouco maior do que em $\mathrm{SC}$, que apresentou valores de -1,70 MPa e -2,38 MPa, respectivamente. A diminuição do $\psi_{\text {mín }}$ foi ocasionada pela intensificação do déficit hídrico durante esses dias, o que causou a diminuição do potencial da água no solo $\left(\psi_{\mathrm{s}}\right)$ em ambos os sistemas e, conseqüentemente, do $\psi_{\text {mín }}$ (Tabela 1).

Nos dois últimos dias de leitura, 78 e $88 \mathrm{DAE}$, o $\psi_{\text {mín }}$ foi igual em ambos os sistemas, tendo apresentado valores de -1,5 MPa em SD e -1,7 MPa em SC. Esse aumento no $\psi_{\text {mín }}$, em relação aos dias anteriores, resultou de precipitações ocorridas a partir dos $69 \mathrm{DAE}$, que possibilitaram o aumento do conteúdo de água no solo e a recuperação hídrica das plantas. Como, nesse período, o $\psi_{\text {mín }}$ foi maior em SD, as plantas cultivadas sob esse sistema apresentaram uma melhor condição hídrica do que aquelas em SC.

Nas parcelas com irrigação, o $\psi_{\text {mín }}$ apresentou diferenças entre os sistemas de manejo durante os dias analisados (Figura 2). Dos 42 aos 58 DAE, a diferença foi muito pequena; o maior $\psi_{\text {mín }}$ ocorreu em SD, durante
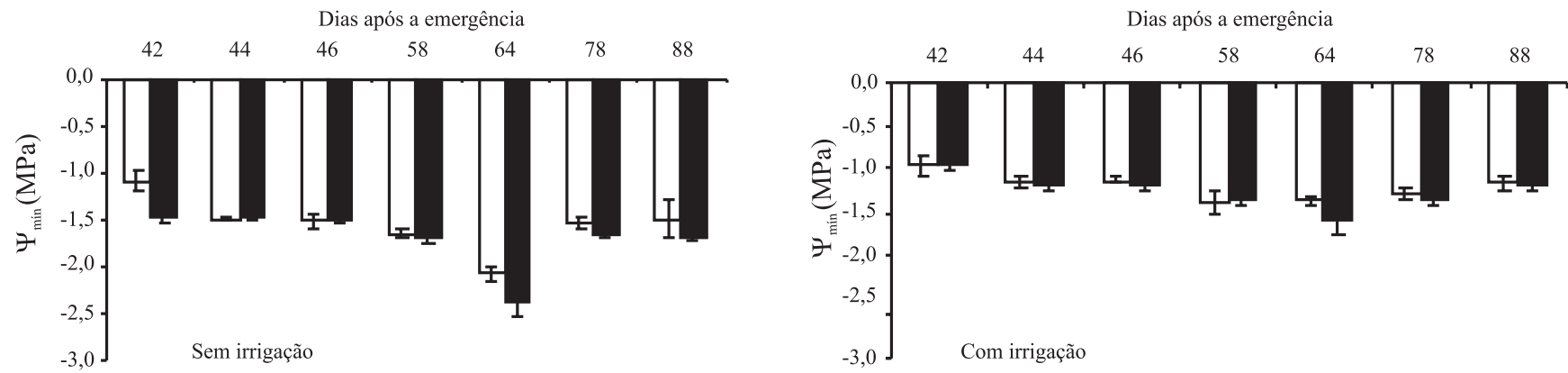

Figura 2. Potencial mínimo de água na folha ( $\left.\psi_{\text {mín }}\right)$, em milho cultivado em semeadura direta $(\square)$ e convencional ( $\square$ ), com irrigação e sem irrigação, no período de 42 a 88 dias após a emergência. Barras nas colunas representam o desvio-padrão da média. EEA/UFRGS, Eldorado do Sul, RS, 2002/2003.

Tabela 1. Potencial matricial da água no solo (MPa), a 45 e $60 \mathrm{~cm}$ de profundidade, em semeadura direta (SD) e convencional (SC), com irrigação (I) e sem irrigação (NI), em relação a dias após a emergência (DAE). EEA/UFRGS, Eldorado do Sul, RS, $2002 / 2003$.

\begin{tabular}{|c|c|c|c|c|c|c|c|c|}
\hline \multirow[t]{2}{*}{ DAE } & \multicolumn{2}{|c|}{ SDNI } & \multicolumn{2}{|c|}{ SCNI } & \multicolumn{2}{|c|}{ SDI } & \multicolumn{2}{|c|}{ SCI } \\
\hline & $45 \mathrm{~cm}$ & $60 \mathrm{~cm}$ & $45 \mathrm{~cm}$ & $60 \mathrm{~cm}$ & $45 \mathrm{~cm}$ & $60 \mathrm{~cm}$ & $45 \mathrm{~cm}$ & $60 \mathrm{~cm}$ \\
\hline 42 & $-0,0379$ & $-0,0140$ & $-^{(1)}$ & $-0,0240$ & $-0,0242$ & $-0,0091$ & $-0,0442$ & $-0,0219$ \\
\hline 44 & $-0,0689$ & $-0,0244$ & - & $-0,0380$ & $-0,0270$ & $-0,0148$ & $-0,0736$ & $-0,0323$ \\
\hline 46 & - & $-0,0408$ & - & $-0,0781$ & $-0,0105$ & $-0,0026$ & $-0,0340$ & $-0,0242$ \\
\hline 58 & - & - & - & - & $-0,0192$ & $-0,0061$ & - & - \\
\hline 64 & - & - & - & - & - & $-0,0206$ & - & - \\
\hline 78 & $-0,0232$ & $-0,0108$ & $-0,0783$ & $-0,0133$ & $-0,0118$ & $-0,0027$ & $-0,0237$ & $-0,0217$ \\
\hline 88 & $-0,0048$ & $-0,0038$ & $-0,0090$ & $-0,0030$ & $-0,0042$ & $-0,0018$ & $-0,0132$ & $-0,0095$ \\
\hline
\end{tabular}

(1)Não houve leitura, devido ao rompimento da coluna de mercúrio dos tensiômetros. 
quase todos os dias analisados. Os valores do $\psi_{\text {mín nes- }}$ ses dias não passaram de -1,39 MPa, o que demonstra uma condição hídrica satisfatória das plantas cultivadas, tanto em SD, quanto em SC. Isso ocorreu em razão da disponibilidade adequada de água no solo, observada nessas parcelas.

Aos $64 \mathrm{DAE}$, o $\psi_{\text {mín }}$ foi maior em SD, quando comparado ao SC. Em SC, o $\psi_{\text {mín }}$ foi de -1,59 MPa, menor valor observado entre os sistemas, quando irrigados, fato que pode ser atribuído ao menor $\psi_{\mathrm{s}}$ observado nesse dia, em ambos os sistemas e, também, à elevada demanda evaporativa da atmosfera, determinada, principalmente, pelo alto déficit de saturação do ar (8,3 mm Hg).

Comparando-se os valores do $\psi_{\text {mín }}$, aos $64 \mathrm{DAE}$, com os dos 78 DAE, observa-se um aumento do $\psi_{\text {mín }}$, tanto em SD quanto em SC. Esse aumento pode ser atribuído às precipitações ocorridas (Figura 1) e às irrigações realizadas nesse período, as quais determinaram um aumento na quantidade de água no solo, que possibilitou uma maior absorção de água pelas plantas cultivadas em ambos os sistemas. Aos 88 DAE, não houve diferenças no $\psi_{\text {mín }}$ entre os sistemas de semeadura, provavelmente em razão das precipitações ocorridas, que possibilitaram a recuperação hídrica das plantas.

Durante a execução do experimento, a quantidade de água (precipitação + irrigação) aportada, nos tratamentos irrigado e sem irrigação, foi, respectivamente, de $170 \mathrm{~mm}$ e $68 \mathrm{~mm}$.

Os dados de $\psi_{\text {mín }}$ acompanharam a variação do $\psi_{\mathrm{s}}$, ou seja, quando o $\psi_{\mathrm{s}}$ foi alto, o $\psi_{\text {mín }}$ também foi elevado, tendo sido maior em SD, na maioria dos dias de leitura.

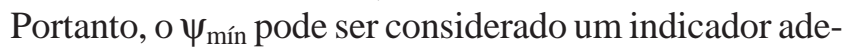
quado da condição hídrica das plantas, pois ressaltou as diferenças em relação ao conteúdo de água no solo e, conseqüentemente, entre os sistemas de manejo. Isso ocorreu porque o sistema de semeadura direta alterou as propriedades físicas do solo, ligadas à dinâmica da água, e proporciou maior disponibilidade hídrica em SD (Dalmago, 2004).

Embora a literatura não apresente estudos que demonstrem diferenças de comportamento do potencial da água na planta, em SD e SC, a mesma é rica em estabelecer as relações entre a quantidade de água disponível no solo e o potencial de água na folha (Kramer \& Boyer, 1995; Bergonci \& Pereira, 2002; Li et al., 2002).

Durante quase todo o período de medida, o potencial de pressão $\left(\psi_{\mathrm{p}}\right)$ manteve-se com valores abaixo de 0,4 MPa, em razão dos baixos $\psi_{\text {mín }}$ observados nessas parcelas (NI) (Figura 3). Apenas aos $42 \mathrm{DAE}$, o $\psi_{\mathrm{p}}$ foi superior a 0,4 $\mathrm{MPa}$, em razão do elevado $\psi_{\text {mín }}$ em SD. Dos 44 aos 78 DAE, o $\psi_{\mathrm{p}}$ foi baixo ou até nulo, em ambos os sistemas, em razão da situação de déficit hídrico que se estabeleceu (Figura 1). Somente aos 88 DAE houve uma semelhança nos valores do $\psi_{\mathrm{p}}$, em razão da recuperação hídrica das plantas.

Quando o $\psi_{\mathrm{p}}$ foi nulo, aos 46, 64 e $78 \mathrm{DAE}$, pode ter ocorrido uma intensa desidratação da célula, a qual foi, provavelmente, acompanhada por um processo ativo de produção de solutos - ajuste osmótico (AO) (Figura 4). Isso ocorreu apenas aos 46 e $64 \mathrm{DAE}$, pois aos $78 \mathrm{DAE}$ as células das plantas cultivadas sob SD entraram, provavelmente, em um processo de desidratação celular, não tendo-se observado, no mesmo dia, o mecanismo de ajuste osmótico. Com o aumento do $\psi_{\mathrm{p}}$ aos $88 \mathrm{DAE}$,

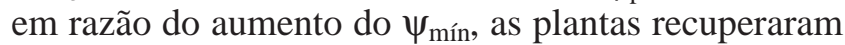
sua condição hídrica.

Nas parcelas com irrigação (I), o $\psi_{\mathrm{p}}$ apresentou valores mais elevados do que nas parcelas sem irrigação,

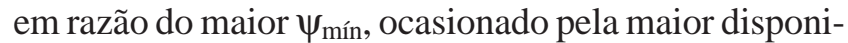
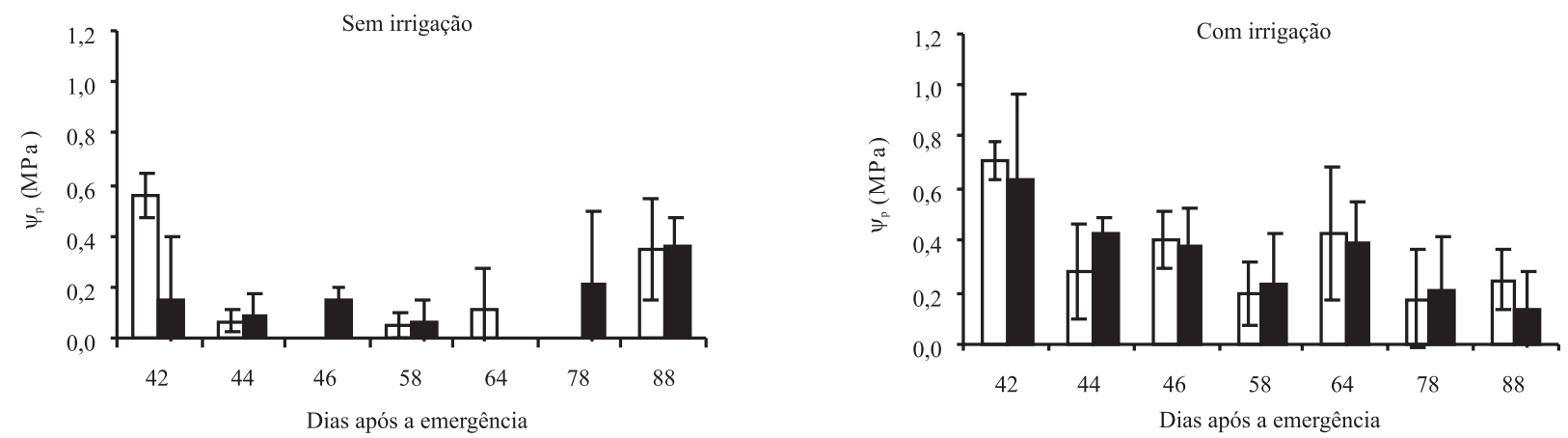

Figura 3. Potencial de pressão $\left(\psi_{\mathrm{p}}\right)$, em milho cultivado em semeadura direta $(\square)$ e convencional ( $\square$ ), com irrigação e sem irrigação, no período de 42 a 88 dias após a emergência. Barras nas colunas representam o desvio-padrão da média. EEA/ UFRGS, Eldorado do Sul, RS, 2002/2003. 
bilidade de água no solo. $\mathrm{O} \psi_{\mathrm{p}}$ nessas parcelas foi ora maior em SD, ora maior em SC.

A diminuição do $\psi_{\mathrm{p}}$, observada tanto nas parcelas irrigadas quanto nas sem irrigação, pode ter influenciado o crescimento celular, que depende do $\psi_{\mathrm{p}}$, para que ocorra a expansão celular (Boyer, 1970). Diminuição do $\psi_{\mathrm{p}}$ foi observado em milho (Premachandra et al., 1992), e em trigo (Bajji et al., 2001), em razão do déficit hídrico, que causou diminuição do conteúdo de água no solo, e conseqüentemente do $\psi_{\text {mín }}$.

Isso demonstra que a resposta geral das plantas de milho, em situação de déficit hídrico, é a diminuição do $\psi_{\text {mín }}$ em razão do menor conteúdo de água no solo, que leva também à diminuição do $\psi_{\mathrm{p}}$ celular. Essa queda do $\psi_{\text {p }}$ pode ou não afetar o crescimento da planta, dependendo da intensidade do déficit hídrico. Em déficit hídrico intenso, a planta pode desenvolver o mecanismo de ajuste

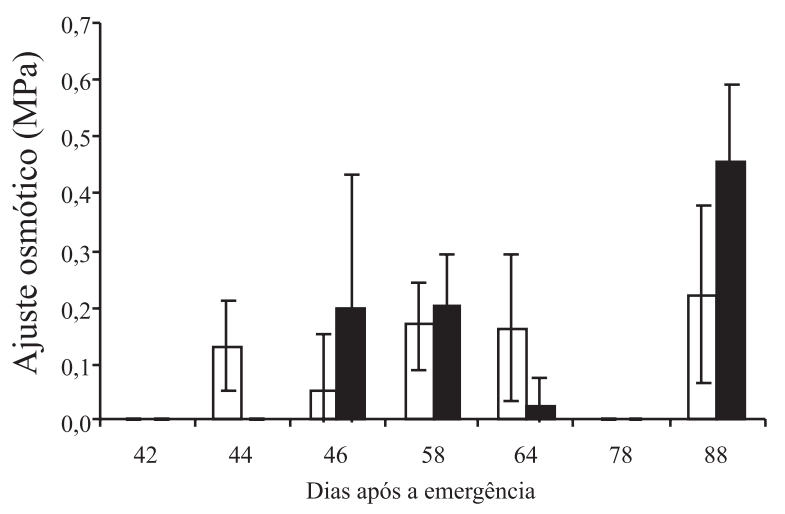

Figura 4. Ajuste osmótico de milho cultivado em semeadura direta ( $\square$ ) e convencional ( $\square$ ), no período de 42 a 88 dias após a emergência. Barras nas colunas representam o desvio-padrão da média. EEA/UFRGS, Eldorado do Sul, RS, 2002/2003. osmótico (Morgan, 1984), que contribui para manter as atividades fisiológicas das plantas, mesmo em baixos potenciais da água.

O potencial osmótico hidratado $\left(\psi_{\mathrm{oh}}\right)$, nas parcelas sem irrigação, apresentou valores menores do que nas parcelas irrigadas, na maioria dos dias (Figura 5). Houve pequenas diferenças entre os sistemas, pois em dois dos sete dias analisados, o $\psi_{\text {oh }}$ foi maior em SD. Nas parcelas irrigadas, o $\psi_{\text {oh }}$ apresentou pequenas variações entre sistemas; na maioria dos dias foi maior em $\mathrm{SD}$, o que caracteriza, novamente, uma melhor condição hídrica das plantas nesse sistema.

Diminuição no $\psi_{\mathrm{oh}}$ também foi observada por Jensen et al. (2000) ao estudarem as relações hídricas de Chenopodium quinoa com déficit hídrico no solo. Em um estudo com diferentes cultivares de trigo, Bajji et al. (2001) também observaram queda no $\psi_{\text {oh }}$, em razão do déficit hídrico, a qual foi mais acentuada em folhas que ainda estavam em crescimento. Em todos esses estudos, a diminuição do $\psi_{\mathrm{oh}}$ ocorreu em resposta a uma situação de déficit hídrico, que ocasionou uma produção ativa de solutos, caracterizando a ocorrência de ajuste osmótico.

Houve ajuste osmótico (AO) em ambos os sistemas; a freqüência foi maior em $\mathrm{SD}$, porém foi mais intenso em SC (Figura 4).

$\mathrm{O}$ AO, em ambos os sistemas, ocorreu em resposta ao déficit hídrico, que ocasionou queda no $\psi_{\text {mín }}$. Em resposta a essa diminuição, as plantas produziram solutos que ocasionaram diminuição do $\psi_{\text {oh }}$ que, por sua vez, atraiu água para dentro da célula, e manteve, assim, a turgescência celular.

O AO não ocorreu em todos os dias de medições. Isso pode ter sido causado pela condição de estresse anterior a esses períodos (42 e $78 \mathrm{DAE}$ ), pois se o déficit hídrico não
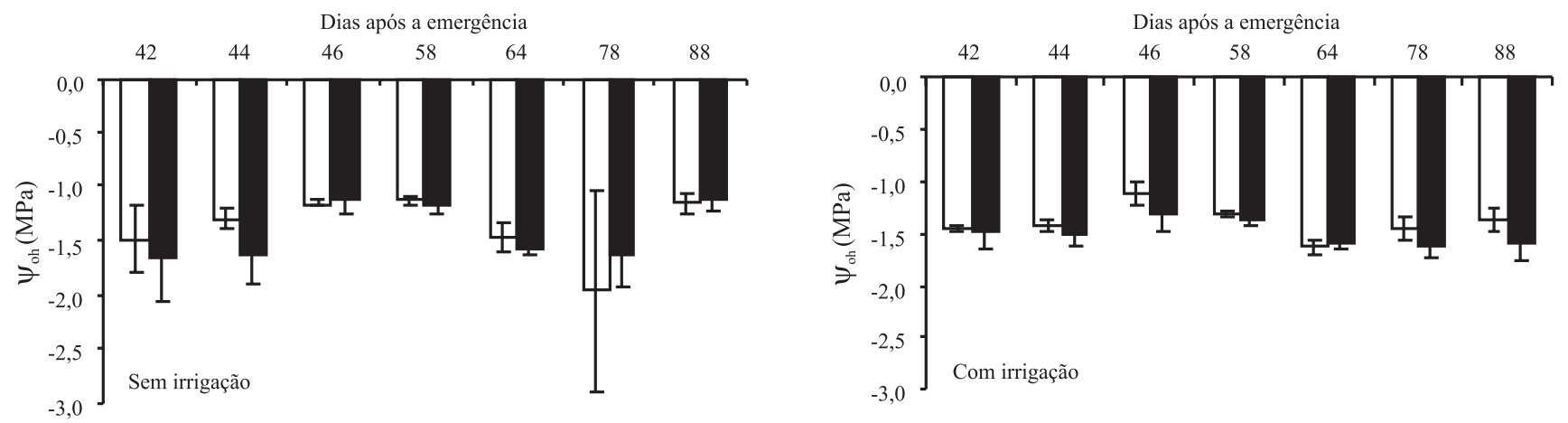

Figura 5. Potencial osmótico hidratado $\left(\psi_{\mathrm{oh}}\right)$, em milho cultivado em semeadura direta $(\square)$ e convencional ( $\square$ ), com irrigação e sem irrigação, no período de 42 a 88 dias após a emergência. Barras nas colunas representam o desvio-padrão da média. EEA/UFRGS, Eldorado do Sul, RS, 2002/2003. 
for muito intenso, o decréscimo no potencial osmótico não é suficiente para causar o ajuste (Morgan, 1984).

Com a ocorrência do AO, as plantas de milho demonstraram que possuem um mecanismo de tolerância ao déficit hídrico, e podem expressar seu rendimento potencial sob uma situação de restrição de água.

Se a restrição de água ocorrer exatamente no período crítico da cultura, o rendimento final será diminuído (Bergamaschi et al., 2004), e o ajuste osmótico pode não ser suficiente para determinar o rendimento potencial da cultura.

\section{Conclusões}

1. O potencial mínimo da água na folha é maior em semeadura direta do que em semeadura convencional.

2. A cultura do milho apresenta mecanismo de tolerância ao déficit hídrico, mediante ajuste osmótico, que ocorre em ambos os sistemas de manejo do solo, porém é mais intenso em semeadura convencional.

3. O potencial mínimo da água na folha pode ser utilizado como indicador do estado hídrico em milho.

\section{Referências}

BAJJI, M.; LUTTS, S.; KINET, J-M. Water deficit effects on solute contribution to osmotic adjustment as a function of leaf ageing in three durum wheat (Triticum durum Desf.) cultivars performing differently in arid conditions. Plant Science, v.160, p.669-681, 2001.

BERGAMASCHI, H.; DALMAGO, G.A.; BERGONCI, J.I.; BIANCHI, C.A.M.; MÜLLER, A.G.; COMIRAN, F.; HECKLER, B.M.M. Distribuição hídrica no período crítico do milho e produção de grãos. Pesquisa Agropecuária Brasileira, v.39, p.831-839, 2004.

BERGAMASCHI, H.; GUADAGNIN, M.R.; CARDOSO, L.S.; SILVA, M.I.G. da. Clima da estação experimental da UFRGS (e região de abrangência). Porto Alegre: UFRGS, 2003. 77p.

BERGONCI, J.I.; BERGAMASCHI, H.; BERLATO, M.A.; SANTOS, O.S. Potencial da água na folha como um indicador de déficit hídrico em milho. Pesquisa Agropecuária Brasileira, v.35, p.1531-1540, 2000.

BERGONCI, J.I.; PEREIRA, P.G. Comportamento do potencial da água na folha e da condutância estomática do milho em função da fração de água disponível no solo. Revista Brasileira de Agrometeorologia, v.10, p.229-235, 2002.

BOYER, S.J. Leaf enlargement and metabolic rates in corn, soybean and sunflower at various leaf water potentials. Plant Physiology, v.46, p.233-235, 1970.

DALMAGO, G.A. Dinâmica da água no solo em cultivos de milho sob plantio direto e preparo convencional. 2004. 244p. Tese (Doutorado) - Universidade Federal do Rio Grande do Sul, Porto Alegre.
DERPSCH, R.; SIDIRAS, N.; ROTH, C.H. Results of studies made from 1977 to 1984 to control erosion by cover and no-tillage techniques in Paraná, Brasil. Soil \& Tillage Research, v.8, p 253263, 1986.

EMBRAPA. Centro Nacional de Pesquisa de Solos (Rio de Janeiro, RJ). Sistema brasileiro de classificação de solos. Rio de Janeiro: Embrapa-CNPS, 1999. 412p.

GRIFFITH, D.R.; MONCRIEF, J.F.; ECKERT, D.J.; SWAN, J.B.; BREITBACH, D.D. Crop response to tillage systems. In: GRIFFITH, D.R.; MONCRIEF, J.F.; ECKERT, D.J.; SWAN, J.B.; BREITBACH, D.D. Conservation tillage systems and management: crop residue management with no-till, ridge-till, mulchtill. Ames: Midwest Plan Service, 1992. p.25-33.

HSIAO, T.C. Plant response to water stress. Annual Review of Plant Physiology, v.24, p.519-570, 1973.

JENSEN, C.R.; JACOBSEN, S.E.; ANDERSEN, M.N.; NÚÑEZ, N.; ANDERSEN, S.D.; RASMUSSEN, L.; MOGENSEN, V.O. Leaf gas exchange and water relation characteristics of field quinoa (Chenopodium quinoa Willd.) during soil drying. European Journal of Agronomy, v.13, p.11-25, 2000.

JONGDEE, B.; FUKAI, S.; COOPER, M. Leaf water potential and osmotic adjustment as physiological traits to improve drought tolerance in rice. Field Crops Research, v.76, p.153-156, 2002.

KRAMER, P.J.; BOYER, J.S. Water relations of plants and soils. San Diego: Academic Press, 1995. 495p.

LI, Y.; FUCKS, M.; COHEN, S.; WALLACH, R. Water uptake profile response of corn to soil moisture depletion. Plant, Cell and Environment, v.25, p.491-500, 2002.

MATZENAUER, R.; BERGAMASCHI, H.; BERLATO, M.A.; RIBOLDI, J. Relações entre rendimento de milho e variáveis hídricas. Revista Brasileira de Agrometeorologia, Santa Maria, v.3, p.8592, 1995.

MORGAN, J.M. Osmoregulation and water stress in higher plants. Annual Review of Plant Physiology, v.35, p.299-319, 1984.

PATAKAS, A.; NIKOLAOU, N.; ZIOZIOIU, E.; RADOGLOU, K.; NOITSAKIS, B. The role of organic solute and ion accumulation in osmotic adjustment in drought-stressed grapevines. Plant Science, v.163, p.361-367, 2002.

PENMAN, H.L. Natural evaporation from open water, bare soil, and grass. Proceedings of Royal Society-Serie A, v.193, p.120145, 1948.

PREMACHANDRA, G.S.; SANEOKA, H.; FUJITA, K.; OGATA, S. Osmotic adjustment and stomatal response to water deficits in maize. Journal of Experimental Botany, v.43, p.1451-1456, 1992.

SERRAJ, R.; SINCLAIR, T.R. Osmolyte accumulation: can it really help increase crop yield under drought conditions? Plant, Cell and Environment, v.25, p.333-341, 2002.

SIDIRAS, N.; DERPSCH, R.; MONDARDO, A. Influência de diferentes sistemas de preparo do solo na variação da umidade e rendimento da soja, em latossolo roxo distrófico (Oxisol). Revista Brasileira de Ciência do Solo, v.7, p.103-106, 1983. 